
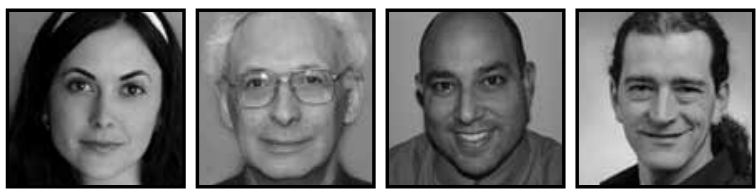

\title{
The Impact of Emotions on Divergent Thinking Processes: A Consideration for Inquiry-Oriented Teachers ${ }^{1}$
}

\author{
Krista C. Ritchie, IWK Health Centre \\ Bruce M. Shore, McGill University \\ Frank LaBanca, Education Connection \\ \& Aaron J. Newman, Dalhousie University
}

\begin{abstract}
Innovation is a cornerstone of the success of our global society and it is required to generate solutions to today's challenges. Students will benefit from classrooms that encourage creative thought and innovative self-directed projects. Inquiry is an instructional approach that fosters creativity and divergent thinking. This paper elaborates on one aspect of the creative process - the impact of emotions on divergent thinking. Theory and some existing research are reviewed and a plan for a neurocognitive study using electroencephalography is delineated. Current and previous research is taken into account when reflecting on suggestions for fostering learning environments conducive to creativity and building interdisciplinary collaboration.
\end{abstract}

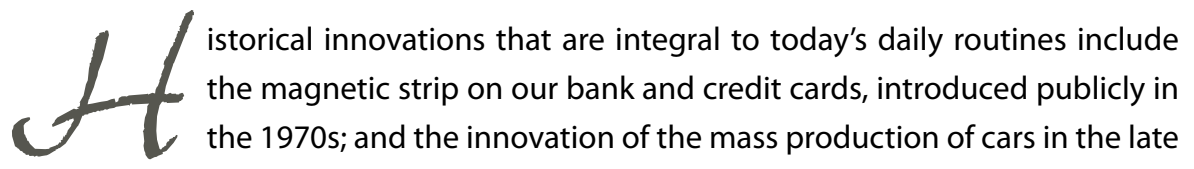
1800s. The leaders of these innovations could not have predicted the impact they have made on today's global economy, physical landscape, and environment. We do not know where our most recent innovations are taking us, but there is little doubt that they are changing our paths and allowing for a future that would otherwise not be possible. 
How do we nurture the skills necessary for our students to become tomorrow's leaders of innovation? Students will benefit from teachers who understand where good ideas come from and how individuals engage in the creative process. This paper discusses some of the ways this area of inquiry is being tackled, particularly, the work of the authors to better understand one intrapersonal aspect of the creative process - testing the impacts of emotions on divergent thinking processes in an electroencephalography experiment.

\section{Innovation and Creativity: An Educational Goal for the $21^{\text {st }}$ Century}

Every person benefits greatly from innovative people and groups. YouTube's (http://www.youtube.com/t/press_timeline) 2005 launch and Wikileaks' (http://wikileaks.org/) official launch in 2007 revolutionized media, how we engage with it, and our level of comfort with sharing and consuming information that has previously been deemed private for individuals, corporations, and governments. A landmark scientific discovery was made in 2010 with the first synthetic cell invented by J. Craig Venter and team: http://www.science mag.org/content/329/5987/52.abstract, http://www.guardian.co.uk/science/video/ 2010/jun/04/craig-venter-synthetic-genomics?INTCMP=ILCNETTXT3486. This innovation is expected to lead to new vaccinations and is imagined to lead to new avenues for tackling disease and improving health. BIXI, a term coined from the combination of bicycle and taxi, is a transportation system implemented successfully in Canada in 2009. BIXI has provided a novel solution for urbanites seeking affordable, ecologically friendly transportation (https://montreal.bixi.com/) by allowing people to make one-way trips with city-owned bikes. These are only three specific examples of how today's innovations can impact any and every aspect of today's society.

Innovation and the creative process are topics of interest across a wide array of professional groups. The journalist, Steven Johnson (2010), wrote a book and gave a TED Talk Where Good Ideas Come From wherein he discussed sociological contexts in which good ideas flourish (http://www.ted.com/talks/steven_johnson_where_ good_ideas_come_from.html). The question "Where do good ideas come from?" has been asked by many academics and teachers alike. The elusive "Eureka!" moment is not as romantic and spontaneous as it is generally understood to be. Johnson explained the slow process of Darwin's theoretical developments and the role of the Enlightenment Era salons and English coffee houses (see Fig. 1) in exchanging ideas 


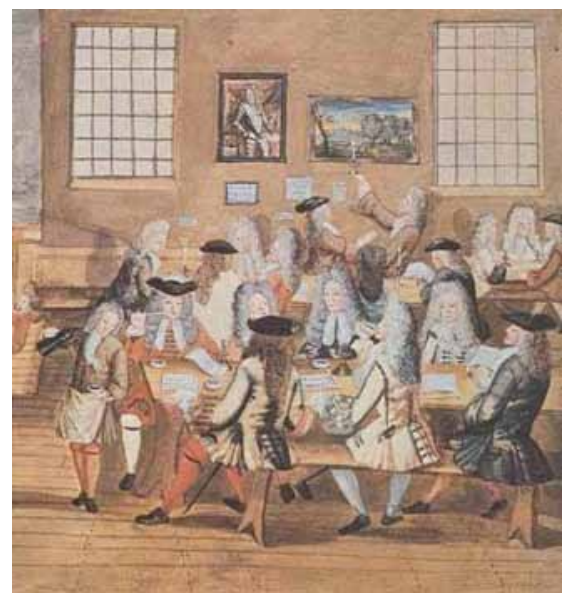

Fig. 1: Poet's artwork

and making unpredictable connections that lead to innovations-eventually. Johnson referred to this process as the slow hunch.

How do we teach students to generate their own slow hunches? How do we make our classrooms look more like $18^{\text {th }}$ century coffee houses (with a fuller representation of cultures and sexes)? How long does a classroom-based slow hunch take? Johnson (2010) did not speak directly to educators, but there is much to be gleaned from examples of creative best practices when planning and enacting inquiry-learning contexts that hope to achieve such high-level learning outcomes.

\section{Understanding Creativity in the Inquiry Classroom and Neurocognitive Laboratory}

Developing the individual ability to create novel ideas of importance to society is an educational goal of great importance. Such creativity can be fostered in any subject area, and at any age. Shore, Birlean, Walker, Ritchie, LaBanca, and Aulls (2009) defined inquiry-literacy and outlined vignettes of what inquiry can look like in science, social studies, and mathematics. Inquiry is a multifaceted, student-centered approach to learning that focuses on creating opportunities for students to engage in interest-driven active learning. In inquiry learning environments, students' interests direct learning activities. Each student has the opportunity to create his or her own research question or project to pursue. Taking a more active role requires students to 
take some responsibility for their learning and results in a sense of ownership over the knowledge constructed in the class. Such classes are nurturing contexts for creativity because there are many open-ended problem spaces. When a specific response is not sought by close-ended activities or evaluations, students are able to make connections and contributions to the class not necessarily anticipated by the teacher. Problem finding, one of the more creative tasks in the inquiry process, is when a student comes up with a novel question (or novel means for answering a previously asked question) that has relevance to an outside audience (Hayes, 1989; LaBanca, 2008; Ritchie, 2009).

Necessary to all problem finding and other creative acts that lead to innovation is the ability to think divergently-outside the box. To see a novel angle on an old problem, or to generate a question that has not previously been asked. Divergent thinking ranges from creating artificial cells that will change the face of medicine to the everyday ingenuity of finding ways to stick to a budget, drawing, or creating a new recipe for dinner. Divergent thinking is a cognitive process necessary for largeand small-scale creativity that can be engaged in everyday. For benefits of everyday creativity see: http://www.psychologytoday.com/articles/200910/everyday-creativity.

The skill of being able to generate novel and useful ideas can be informed by emerging work in the cognitive and neurological sciences. Breaking down the problem-finding process in applied studies has been the work of LaBanca (2008) and Ritchie (2009). LaBanca (2008) studied high school students who presented their selfdirected projects at a statewide science fair and at the 2007 International Science and Engineering Fair in a multi-case qualitative study. Through interviews, document analyses, and surveys, LaBanca explored the process and outcomes of problem finding from the perspectives of students, teachers, mentors, and fair directors. Through retrospective accounts, the problem-finding process was reported as being idiosyncratic, nonlinear, and flexible, similar to the findings of Getzels and Csikszentmihalyi's (1976, see p. 27 of introduction) study of art students. This result indicated to LaBanca that this truly student-directed form of inquiry might open doors to creative and analytical thought that might not be present in other forms of instruction. Ritchie (2009) looked closely at similar students engaging in the same open-ended inquiry process to document some of the details of students' experiences with this creative and flexible process as it unfolded through the school year. Ritchie found that students who engaged in problem finding had more intense emotional experiences during class time compared to students in inquiry classes not required to problem find, from the full range of positive to negative as assessed by the Positive and Negative Affect Questionnaire (Watson \& Clark, 1994). The heightened emotions that participants 
reported were interpreted to be due to the personal investment required to engage creatively, to put themselves into their schoolwork in a way not typically required of them. Results from these naturalistic studies inspired a leap from classroom to laboratory to shed more (and different) light on how emotions impact divergent thinking. Divergent thinking is our cognitive process of interest because it was evident during Ritchie's classroom observations that thinking divergently was key to students coming up with novel research questions. It was clear from classroom observations and student and teacher interviews that divergent thinking was a common and important component of their creative processes.

Advances in the neurosciences are not finding one (or even three or four) specific brain regions associated with creative thought or insight experiences. Dietrich and Kanso (2010) published a review of 63 articles (reporting 72 experiments) exploring the neural mechanisms of insight and creativity. Neuroimaging results only showed diffuse prefrontal activation and EEG studies had inconsistent results across studies. An inconclusive picture was also drawn based on artistic creativity studies. Given that creative and insightful acts comprise many specific cognitive processes and brain regions, it is not surprising that results were varied. Lack of evidence certainly does not call into question the existence or importance of studying the creative process. Instead, cognitive researchers need to identify component processes critical to creativity that can be operationalized, isolated, and observed within the necessary constraints of experimental cognitive neuroscience. The moment of insight, the stroke of genius that many creative people crave, might be an identification of the moment when all of the necessary and slowly evolving pieces come together. An innovation is the outcome of the dynamic relationships between the social settings, the time frame required for its development, interpersonal dynamics between collaborators, and the intrapersonal dynamics within each collaborator. People are social and cultural beings who have constant interaction between their interpersonal and intrapersonal processes (Vygotsky, 1978). Cognitive neuroscience is well equipped to inform some of the intrapersonal components of the creative process.

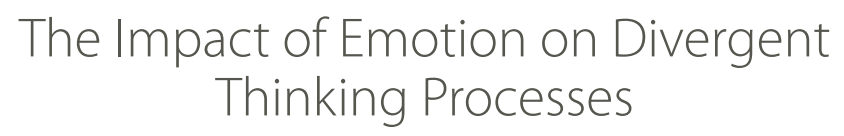

Barbara Fredrickson's (1998, 2004) Broaden and Build Theory of Positive Emotions explains that positive emotions have an evolutionary function, which is to broaden people's perspectives. Broadening encourages people to pursue a 
wider range of thoughts and actions than is typical for an individual or social context. Activities that evoke positive emotions, such as interest, joy, and excitement should broaden people's thought-action repertoires. "Experiences of certain positive emotions prompt individuals to discard time-tested or routine behavioral scripts and to pursue novel, creative, and often unscripted paths of thought and action" (Fredrickson, 1998, p. 304). Negative emotions, on the other hand, are theorized to be associated with the narrowing of thought-action repertoires. This proposition stems from an evolutionary perspective; quick, concise, and convergent thinking is functional in threatening situations.

Interest is an emotion that occurs in social contexts that are safe and offer a sense of novelty, possibility, or mystery (Izard, 1977). Social contexts conducive to feeling interested are also perceived as important and demanding of attention and effort. An interested mind is broadened in that it evokes a mindset of openness to new ideas and experiences. The thought-action tendency resultant from interest is exploration with the goal of increasing knowledge and experience. Openness and willingness to take action to explore builds on existing knowledge structures (Fredrickson, 1998). Contentment is a family of emotions that includes tranquility and serenity, and which is most often experienced in safe social contexts that have a high degree of certainty. When content, people are able to savor current life situations and accomplishments. This is a time for holistic reflection and relation of self to larger social cultural contexts. The outcome of this thought-action repertoire is a building of cognitive resources; reflection leads to strengthened knowledge structures and perspective about who you are and what you think in relation to others. Play and exploration are likely when experiencing positive emotions and the associated thought-action repertoires promote discovery of novel ideas and actions. There is empirical evidence to support the theory that momentary emotional experiences change cognitive perspective; people in positive moods tend to be global information processors, whereas people who are sad tend to narrow their attention and focus on the specifics of a situation (Gasper, 2004). No study has yet to use ERP methods for tasks that require participants to engage in divergent thinking while induced into specific positive or negative emotion states.

What is the advantage of understanding emotions' influences on divergent thinking? How does the above theory apply to teaching and learning? Learning activities that minimize negative emotions are hypothesized to also minimize narrowed focus and convergent ways of thinking. Activities that evoke positive emotions, such as interest, joy, and excitement, are hypothesized to broaden students' thought-action repertoires and lead to student-directed creative endeavors. It is not our goal 
to create a global dichotomy between the benefits of positive emotion states and the disadvantages of negative emotions. Inquiry students reported significantly more negative emotions (Ritchie, 2009) than their peers in teacher-directed classrooms. Both positive and negative emotions might be inevitable, and can have their benefits. Having an eye for detail and a narrow focus might be beneficial for some specific tasks involved in the research process, but innovation cannot be achieved without the divergent thinking hypothesized to be more likely during positive than negative emotion states.

\section{A Neurocognitive Research Study in the Making}

We are in the beginning stages of collecting data for a study that we describe briefly here in order to exemplify how we can test the above directional hypotheses using neurocognitive methods. It would be premature to assume that our hypotheses will be confirmed. The goal of this paper is to invite a multidisciplinary conversation about the role of cognitive neuroscience in building evidence to support creativity in best inquiry practices.

Barbara Fredrickson's theory of positive emotions proposes that positive emotion states lead to broadened perspective taking and cognitive flexibility, and inversely, that negative emotions have narrowing effects on these processes. Do people perform differently in tasks that require divergent thinking when happy versus serene versus sad versus disgusted? We plan to test this theory by inducing participants into one of four emotion states (happy, serene, sad, or disgust) and having them complete divergent thinking tasks that assess their cognitive flexibility in an event-related potential (ERP) experiment using electroencephalography (EEG). These four emotion states were selected because they are distinct from each other and have been used in previous studies requiring emotion induction in laboratory settings. There are many nuanced positive and negative emotions that might be more applicable to a classroom setting (e.g., interest, anxiety, frustration), but are more difficult to induce in an experimental context. Our first goal is to look for evidence of differences between positive and negative emotion states in general. If our hypotheses are confirmed, future work could begin to explore a wider range of emotional experiences.

Emotions will be induced by watching emotionally salient videos during the laboratory task. After participating in the ERP experiment with the videos, participants will be asked to complete a self-report assessment of a full range of emotional 
experiences in order to confirm how they were feeling. Emotions extraneous to the assigned conditions will be used as a covariate in the analysis of results. Participants who did not adequately report emotional experiences in line with the group to which they were randomly assigned will be removed from analysis and their performance will be reported separately.

Electroencephalography (EEG) is a non-invasive measure of electrical brain activity by nodes attached to a cap that is worn on the head. An EEG is a recording of electrical signals from the brain made by placing electrodes (small metal discs) on the scalp. The electrodes are generally in a net (like a hair net) that is placed on the participant's head. These electrodes pick up electrical signals that are naturally produced by the brain, and send them to a computer where they can be stored and later analyzed. EEGs allow us to follow electrical impulses across the surface of the brain and observe changes over split seconds of time.

The event-related potential technique (ERP) collects electrophysiological data through EEG. ERPs are designated potentials that have reliably displayed relationships between timing of a specific positive or negative voltage and a definable event. ERPs measure how long it takes the brain to process stimuli or to perform specific cognitive processes during researcher-constructed and highly controlled tasks in experiments. The timing measured for specific electrophysiological responses are within milliseconds of the stimuli being presented to the participant on a computer screen. Electrophysiological recordings are relatively variable between repeated events. Results that are interpreted in studies are an average of voltages measured over multiple trials (often hundreds). Over decades of research, many responses have been generally agreed to be associated with specific processes. For example, the N100 wave (a voltage detected with a latency of approximately 80-140 milliseconds after stimulus presentation) is sensitive to attention (Parasuraman, 1980; Luck, 2005). This means there is a dip in voltage at approximately 100 milliseconds after presentation of a stimulus if a participant is paying attention. There is something appealing about the notion of actually being able to document whether or not a student is paying attention! The N400 wave has been associated with identification of incongruency during cognitive tasks. For instance, if one word follows another that is highly related ("coffee," then "cream"), there will be no identifiable dip in electrophysiological activity at $\mathbf{4 0 0}$ milliseconds after presentation of the second word. If a word incongruent with the first word is presented ("coffee," then "socks"), there will be a negative voltage detected through EEG at approximately 400 milliseconds. This allows us a way to measure, aside from just asking the participant, if he or she perceives a relationship (or lack of relationship) between two words. 
Divergent thinking is being able to see relationships in unconventional places. Coffee and socks are not so incongruent if you are thinking about ways to warm up on a cold day. Thinking about new uses for common tools is an example of a divergent thinking exercise. How many uses can you think of for a fork? If you only think about eating, you are not thinking divergently. What about combing your hair, using it as a paintbrush to create texture in a painting, cleaning a gritty surface, reshaping it to make jewelry, bending some prongs to make a place-card holder at the dinner table, or hanging many together to make a wind chime? Divergent thinking is a cognitive process that has great implications for education, particularly problem finding in inquiry contexts (Shore, Aulls, \& Delcourt, 2008). Divergent thinking is a fundamental skill for flexible thinking and creativity in brainstorming and ill-defined problem-solving tasks (Hayes, 1989; Newell, Shaw, \& Simon, 1964). A task that assesses divergent thinking that can be completed in an ERP experiment involves presentation of hundreds of word pairs. Participants are asked to rate on a visual-analog scale that is presented on a computer screen the extent to which two words are related, from "not at all related" to "very related." When a participant sees incongruence between the meanings of two words, an N400 is expected to be detectable.

If happiness evokes a readiness for creativity and serenity evokes a reflective mindset to savor previous experiences, then it is hypothesized that participants induced to feel happy will have less activation of the N400 for conventionally incongruent words (both groups will have the same lack of N400 for extremely congruent word pairs). Because of the actual narrowing effects of feeling sad or disgusted, participants induced to feel sad or disgusted are hypothesized to have greater activation of the N400 for conventionally incongruent words (and the same lack of N400 for extremely congruent word pairs) in comparison to participants who feel happy or serene.

This study design has required a little methodological innovation. With the goal of making participants feel authentic and sustained emotional experiences (while randomly assigned to be happy, sad, disgusted, or serene), the team was required to create emotion-induction techniques that would be effective in the EEG laboratory context. Further, divergent thinking has previously been assessed using tasks where participants need to make dichotomous decisions and classify word pairs as congruent or incongruent. There are no shades of grey allowed in the decision making required in traditional congruency tasks. We expect that participants in positive moods will see the shades of grey-it is hypothesized they will see that some words are more or less related to other words. Using a visual analog scale to make judgments of congruency in an ERP experiment is a new and more ecologically valid method for assessing divergent thinking. 


\section{Classroom Involvement and Implications}

In an ideal inquiry classroom, the responsibility for learning is shared between the teacher and students. Students take on more diverse roles, some of which are traditionally the domain of the teacher, and direct what and how they will learn with guidance from their teacher and peers. Ultimately, the goal of inquiry is for students to engage in investigations guided by personal interests. Integrating curricula and students' interests in a meaningful way makes learning a far more personal process, in comparison to studying the content of assigned chapters or practicing word problems. It is logical that greater personal investment would result in heightened emotional experiences. Potential emotional experiences include vulnerability and anxiety around sharing personal thoughts with teachers and peers, confidence to take risks and brainstorm new ideas, excitement when exploring new areas, pride of outcomes. The potential emotional experiences are vast and require further investigation to delineate which are most common in inquiry settings. We recommend that educators be aware of the heightened emotional experiences of students in these open-ended learning environments. Students might need some extra encouragement to open up, they might need a pep talk when their idea does not work, or when they realize they should change their topic for logistical reasons. A teacher's ability to welcome unexpected responses and to tolerate the unproductive phases a student might go through is critical to the success of the truly student-directed inquiry classroom. This is not to say that the teacher needs to attend to all emotional reactions, or even that the student will explicitly share these experiences with his or her teacher. The argument here is that when learning is self-directed, it becomes personal and when something becomes personal, the emotional valence of the learning process increases. An awareness of this aspect of the student experience can help teachers better understand their learners, which will undoubtedly facilitate one's ability to support them through the inquiry process.

Going back to Johnson's explanation of innovation coming from slow hunches, how long does a classroom-based slow hunch take? Students need to be able to have both focused and unproductive phases and to be able to work at their own pace-every student cannot come up with their good idea in one class or even in one week. High school students in an applied science research class took from two weeks to three months to generate a novel research question of personal interest (Ritchie, 2009). This timing was counting from September. Many of the students who participated began conversations with their teacher in the summer months, or even the school year before their Applied Science Research class. It takes time to identify interests, learn more about them, shift focus, look for problem spaces, and finally 
commit to (and complete) a novel and innovative project. For a general discussion of teaching and learning strategies that promote creative problem finding, see LaBanca and Ritchie (2011).

Inquiry classrooms that are flexible and truly student-directed regarding how and when a project unfolds will be breeding grounds for creativity. This flexibility can involve loud conversations among students and teachers, much like $18^{\text {th }}$ century coffeehouses. It will involve students at varying stages of their projects in the same room. Some will have moments of focus and confidence on the same day that others are discouraged or intimidated. Having awareness of the emotional experiences of students will help teachers be able to give students the guidance and support they need to think creatively. One goal of the above study and the team's larger program of research is to describe in detail how emotions relevant to classrooms impact cognitive processes that are the building blocks of creative thought.

\section{Conclusion}

It is necessary to maintain collaborative relationships between the researchers involved in the aforementioned experiment and teachers who share an interest in this work. These teachers, as recommended by Szücs and Goswami (2007), play a critical role by sharing their extensive practical experience to inform research questions and future directions for research. A multiple-methods approach to creating programs of research is called for. Following the tradition of Donald Hebb (1949), we strongly believe that multiple areas of Education and Psychology should collaborate to lead to generalizable theoretical insight. There is a current movement to bridge the divide between research in education and our understanding of the neurocognitive processes involved in learning and emotion (Immordino-Yang, 2008; Szücs \& Goswami, 2007). Applying the important insights gained from neuroimaging research to actual educational settings is a lofty goal whose realization will take some years yet (Nature Neuroscience Editorial, 2006). However, the critical first step in this endeavor is interdisciplinary collaboration in which expertise from both areas is combined.

If we want to integrate neuroscience and education, sending information between education and neuroscience across bridges is not the answer. Simply taking results and interpretations of (cognitive) neuroscience, relating them to an educational context, and then drawing conclusions for education does not integrate the two disciplines. What we really need is a new 
colony of interdisciplinary researchers trained both in cognitive neuroscience and in education. (Szücs \& Goswami, 2007, p. 117)

It is not always feasible to be retrained or to become expert in all areas relevant to our personal interests. It is in new research groups, new social networks (in a coffee shop, university, school, or a Google + group) that areas of expertise can merge and inform each other, forming ideas and generating theoretical insights and pedagogical innovations not otherwise possible. We can build collaborations between research and practice that can be mutually informative. Insights from inquiry teachers have already informed the described study and they are keen to learn of the results. Classroom-based research by this team is being conducted in tandem with the laboratory-based research. If both areas of research triangulate to support the theoretically driven hypotheses, then there would be substantial evidence in support of using this framework to better understand the intrapersonal emotional and cognitive components of students' learning processes. We hope that this discussion serves as an impetus for readers (educators and researchers across disciplines) to contact us and engage in conversations about the evolution of this program of research.

\section{Notes}

1. Parts of this paper were taken from Ritchie's Doctoral Dissertation: Ritchie, K. C. (2009). The process of problem-finding in inquiry education: $A$ focus on students' experiences. Unpublished doctoral dissertation in Educational Psychology, McGill University, Montreal, Quebec.

\section{References}

Dietrich, A., \& Kanso, R. (2010). A review of EEG, $E R P$, and neuroimaging studies of creativity and insight. Psychological Bulletin, 136, 822-848.

Fredrickson, B. L. (1998). What good are positive emotions? Review of General Psychology, 2, 300-319.
Fredrickson, B. L. (2004). The broaden and build theory of positive emotions. Philosophical Transactions of the Royal Society: Biological Sciences, 359, 1367-1377.

Gasper, K. (2004). Do you see what I see? Affect and visual information processing. Cognition and Emotion, 18, 405-421. 
Getzels, J. W., \& Csikszentmihalyi, M. (1976). The creative vision: A longitudinal study of problem finding in art. New York: Wiley.

Hayes, J. R. (1989). The complete problem solver. Hillsdale, NJ: Earlbaum.

Hebb, D. O. (1949). The organization of behavior: A neuropsychological theory. New York: Wiley.

Immordino-Yang, M. H. (2008). The smoke around mirror neurons: Goals as sociocultural and emotional organizers of perception and action in learning. Mind, Brain, and Education, 2(2), 67-73.

Izard, C. E. (1977). Human emotions. New York: Plenum Press.

Johnson, S. (2010). Where good ideas come from: The natural history of innovation. New York: Riverhead Books.

LaBanca, F. (2008). Impact of problem finding on the quality of authentic open inquiry science research projects. Unpublished doctoral dissertation in Educational Leadership, Western Connecticut State University, Danbury, Connecticut.

LaBanca, F., \& Ritchie, K. C. (November, 2011). The art of scientific ideas: Teaching and learning strategies that promote creative problem finding. The Science Teacher, 48-51.

Luck, S. J. (2005). An introduction to the event-related potential technique. Cambridge, Massachusetts: MIT Press.

Nature Neuroscience Editorial. (November, 2006). The science of education reform. Nature Neuroscience, 9, 1345.
Newell, A., Shaw, J. C., \& Simon, H. A. (1964). The process of creative thinking. In $\mathrm{H}$. E. Gruber, G. Terell, and M. Werthiemer (Eds.), Contemporary approaches to creative thinking, Third edition. New York: Atherton Press.

Parasuraman, R. (1980). Effects of information processing demands on slow negative shift latencies and N100 amplitude in selective and divided attention. Biological Psychology, 11(3-4), 217-233.

Ritchie, K. C. (2009). The process of problem-finding in inquiry education: A focus on students' experiences. Unpublished doctoral dissertation in Educational Psychology, McGill University, Montreal, Quebec.

Shore, B. M., Aulls, M. W., \& Delcourt, M. A. B. (Eds.). (2008). Inquiry in Education (vol. II): Overcoming barriers to successful implementation. Mahwah, NJ: Erlbaum.

Shore, B. M., Birlean, C., Walker, C. L., Ritchie, K. C., LaBanca, F., \& Aulls, M. W. (2009). Inquiry literacy: A proposal for a neologism. LEARNing Landscapes, 3(1), 139-155.

Szücs, D., \& Goswami, U. (2007). Educational neuroscience: Defining a new discipline for the study of mental representations. Mind, Brain, and Education, 1(3), 114-127.

Vygotsky, L. S. (1978). Mind in society: The development of higher-order psychological processes (Trans. M. Cole). Cambridge, MA: Harvard University Press.

Watson, D., \& Clark, L. A. (1994). The PANAS-X: Manual for the Positive and Negative Affect Schedule--Expanded Form. Unpublished manuscript, University of lowa. Retrieved April 10, 2009, from www.psychology. uiowa.edu/faculty/Clark/PANAS-X.pdf 


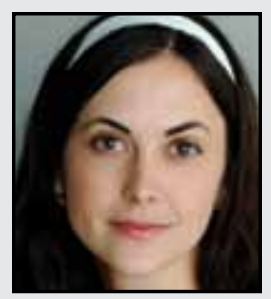

Krista C. Ritchie, PhD, is a Consulting Scientist at the IWK Women's and Children's Health Centre and Adjunct Faculty at Dalhousie University in Halifax, Nova Scotia. As a member of both Dalhousie's Neurocognitive Imaging Laboratory and McGill's High Ability and Inquiry Research Team, she is juxtaposed between laboratory- and applied-research settings that allow her to explore self-directed learning environments, and the role of emotions in learning and divergent thinking. Krista has had post-doctoral training with Aaron Newman and Bruce Shore was her doctoral supervisor.

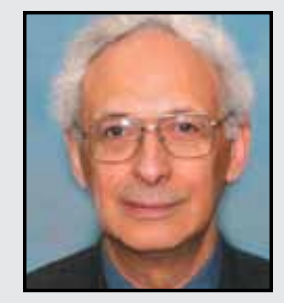

Bruce M. Shore is Emeritus Professor of Educational Psychology in the Department of Educational and Counseling Psychology at McGill University in Montreal, Quebec, and Associate Director (McGill) of the multi-campus Centre for the Study of Learning and Performance. He received his BSC (concentrating in chemistry, mathematics, and psychology), teaching diploma, and MA in Education from McGill, taught high-school mathematics, and then received his PhD in Educational Psychology from the University of Calgary. For 21 years he was jointly appointed as a member of the McGill University's faculty development unit. He has also served as Chair of the Department, President of the McGill Association of University Teachers, and Dean of Students. 


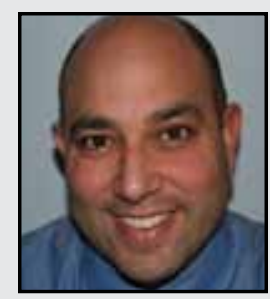

Frank LaBanca, EdD, is the Director of the Center for $21^{\text {st }}$ Century Skills at EDUCATION CONNECTION and adjunct professor of education at Western Connecticut State University in Connecticut, USA. During his 16 -year career in the classroom, he taught high school Biology and Applied Science Research. He has been recognized as a National Education Association Innovation Teacher; a GTE GIFT (Growth Initiatives For Teachers) Fellow; a RadioShack National Teacher for Excellence in Science, Math, and Technology; and the Teachers' Insurance Plan Teacher of the Year. Frank was also recognized by Discovery as the National Outstanding Classroom Blogger for his blog Applied Science Research.

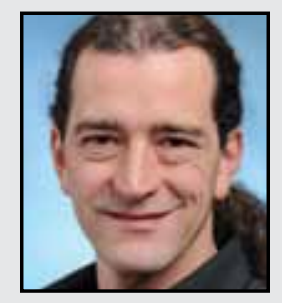

Aaron J. Newman is an Associate Professor in Psychology, Psychiatry, Surgery, and Pediatrics (Division of Neurology) at Dalhousie University, where he directs the NeuroCognitive Imaging Laboratory. $\mathrm{He}$ is affiliated with the Neuroscience Institute and the Brain Repair Centre at Dalhousie, as well as being a staff scientist at both the Queen Elizabeth II and IWK Health Centres in Halifax, Nova Scotia. He is also an affiliate scientist with the National Research Council Institute for Biodiagnostics.

LINKTO:

http://neuroimaging.psychology.dal.ca

http://problemfinding.labanca.net 